\title{
CARACTERIZAÇÃO ESPACIAL E TEMPORAL DA PRECIPITAÇÃO NA COSTA VERDE FLUMINENSE - 2001 A 2016
}

\author{
SPACE AND TEMPORAL CHARACTERIZATION OF PRECIPITATION IN THE GREEN COAST - 2001 TO 2016
}

\author{
Heitor Soares Farias ${ }^{1}$, Gabriela Fernandes Santos Alves ${ }^{1}$ \\ 1 Universidade Federal Rural do Rio de Janeiro " (UFRRJ), Rio de Janeiro, RJ, Brasil
}

Correspondência para: Heitor Soares Farias (heisofa@gmail.com)

doi: 10.12957/geouerj.2019.40955

Recebido em: 16 ago. 2018| Aceito em: 24 out. 2018

\section{RESUMO}

A região da Costa Verde, localizada no sul do estado do Rio de Janeiro, nas últimas décadas tem ganhado destaque pelas tragédias ocorridas em consequência de episódios de chuva intensa, como nos anos de 2002 , 2009/2010 e 2013. O relevo da Serra do Mar, muito próximo ao litoral, se contrapõe especialmente ao deslocamento dos sistemas frontais, contribuindo para a elevada precipitação nesta região. Por outro lado, investimentos econômicos ocorridos em infraestrutura rodoviária e portuária e o reaquecimento da indústria naval, em diferentes momentos levaram muitos migrantes à região, estabelecendo-se nas poucas áreas planas, e por vezes ocupando as encostas íngremes, principalmente em Angra dos Reis, uma das cidades de maior densidade demográfica da Costa Verde fluminense. Desta maneira, utilizando dados diários de pluviosidade de 12 (doze) estações meteorológicas presentes em municípios da Costa Verde e vizinhos no estado de São Paulo, foram construídas tabelas e mapas para compreender a distribuição espacial e temporal da precipitação na área. Os resultados mostraram que em Angra dos Reis são registradas as maiores concentrações de chuva, principalmente nas estações Bracuhy e Mambucaba, onde a população tem sido afetada por inundações e movimentos de massa com perdas materiais e de vidas.

Palavras-chave: Planejamento Ambiental. Inundações. Movimentos de Massa. Rio de Janeiro.

\section{ABSTRACT}

The Green Coast, located in the southern part of the state of Rio de Janeiro, has been highlighted in the last decades by the tragedies that occurred as a consequence of intense rainfall events, such as in the years of 2002, 2009/2010 and 2013. The Serra do Mar mountains, very near to the ocean, is especially opposed to the displacement of the frontal systems, contributing to the high precipitation in this region. On the other hand, economic investments in road and port infrastructure and the reawakening of the naval industry at different times led many migrants to the region, establishing themselves in the few flat areas, and sometimes occupying steep slopes, especially in Angra dos Reis, one of the most densely populated cities in the Green Coast of Rio de Janeiro. Thus, using daily rainfall data from 12 meteorological stations present in Green Coast municipalities and neighbors in the state of São Paulo, tables and maps were constructed to understand the spatial and temporal distribution of precipitation in the area. The results showed that in Angra dos Reis the highest concentrations of rain are recorded, mainly in the Bracuhy and Mambucaba stations, where the population has been affected by floods and mass movements with material losses and lives.

Keywords: Environmental Planning. Floodings. Landslides. Rio de Janeiro.

\section{INTRODUÇÃO}

A região da Costa Verde caracteriza-se pelo encontro da Serra do Mar com o Oceano Atlântico, formando um belo cenário turístico. Esta área estende-se desde Santos-SP por todo o litoral norte do 
estado de São Paulo até o litoral sul do estado do Rio de Janeiro, incluindo os municípios de Paraty, Angra dos Reis, Mangaratiba, Itaguaí e Rio Claro, segundo o Ministério do Turismo (2015) e a Secretaria de Estado de Turismo do Rio de Janeiro (SETUR, 2018).

Por um lado, a Costa Verde exibe um dos destinos mais bonitos da costa brasileira, mas por outro a presença da Serra do Mar, muito próxima ao litoral, forma uma barreira orográfica que se contrapõe ao deslocamento dos sistemas frontais, resultando em índices pluviométricos muito elevados, os maiores do estado do Rio de Janeiro (NIMER, 1979). Os eventos pluviométricos mais intensos podem acarretar desastres naturais de grandes proporções, como aqueles verificados nos anos de 2002, 2009/2010 e 2013 no município de Angra dos Reis.

Em 2002, choveu no dia 9 de dezembro o que era esperado para um período de três meses. A força da água provocou o deslizamento de uma encosta no bairro do Areal que destruiu 70 casas deixando 40 mortos, 100 feridos e mais de 500 pessoas desabrigadas. 0 governo federal liberou $\mathrm{R} \$ 10$ milhões para a reconstrução das moradias das famílias vítimas da tragédia (VIEIRA, 2010).

Em 2009, em Angra dos Reis, a chuva forte que começou na noite de 31 de dezembro provocou um deslizamento de terra na Ilha Grande atingindo a Pousada Sankay e outras sete casas na Enseada do Bananal, onde morreram 31 pessoas. No continente, a chuva ocasionou maiores danos ao centro de Angra dos Reis. Parte do Morro da Carioca deslizou, matando mais 22 pessoas e desalojando outras 250 famílias. 0 governo federal liberou $\mathrm{R} \$ 80$ milhões para a reconstrução das moradias das famílias vítimas da tragédia (O GLOBO, 2010).

Em 2013, desde as primeiras horas do ano, Angra dos Reis registrou chuvas fortes que a deixaram em situação de emergência. A região mais atingida foi a zona oeste da cidade, principalmente nos bairros Bracuí, Santa Rita do Bracuhy, Frade e Parque Mambucaba. Pelo menos oito casas desabaram ferindo 15 pessoas e outras 40 pessoas haviam sido retiradas de suas casas (SEPPI, 2013).

Luiz Silva \& Dereczynski (2014) chamam a atenção para a importância de uma minuciosa investigação da climatologia de uma determinada região, para assim conhecer suas características atmosféricas médias e compreender suas flutuações no decorrer do tempo. Assim é possível se planejar 
diante das variações climáticas, apoiando atividades das mais diversas, desde a agricultura, saúde, até planejamento urbano, defesa civil e gerenciamento de recursos hídricos.

Este planejamento é mais do que necessário, pois o sumário executivo do primeiro Relatório de Avaliação Nacional, o Painel Brasileiro de Mudanças Climáticas (PBMC), feito nos mesmos moldes do relatório do Painel Intergovernamental sobre Mudanças Climáticas (Intergovernmental Panel on Climate Change - IPCC), divulgou que no Brasil o aumento de temperatura será entre $1{ }^{\circ} \mathrm{C}$ e $6{ }^{\circ} \mathrm{C}$ até 2100, em comparação à registrada no fim do século 20. Como consequência, deverá diminuir significativamente a ocorrência de chuvas em grande parte das regiões central, Norte e Nordeste do país. Nas regiões Sul e Sudeste, por outro lado, haverá um aumento do número de precipitações (PBMC, 2013).

Corroborando com essas projeções, Dereczynski et al. (2013) e Luiz Silva et al. (2014) mostraram que dias frios e noites frias têm se tornado menos frequentes na cidade do Rio de Janeiro, enquanto que a frequência de ocorrência de chuvas fortes, dias quentes e noites quentes deverão aumentar. Esses resultados também foram observados para outras áreas do estado do Rio de Janeiro (Luiz Silva e Dereczynski, 2014).

Desta maneira, este trabalho tem como objetivo analisar a distribuição da pluviosidade na região da Costa Verde fluminense, e municípios vizinhos no Estado de São Paulo, compreendendo a distribuição espacial e temporal da pluviosidade na área, com destaque para os eventos extremos de pluviosidade e seus efeitos sobre a desorganização do espaço de Angra dos Reis nos anos de 2002, 2009/2010 e 2013.

\section{Área de Estudo}

A região da Costa Verde Fluminense - municípios de Paraty, Angra dos Reis, Mangaratiba, Itaguaí e Rio Claro -, encontra-se voltada para a Baía de Sepetiba dividindo-se entre a atividade turística e portuária/industrial como principal atividade econômica. A exceção é o município de Rio Claro que não é litorâneo, embora esteja na Serra do Mar que em contato com o Oceano Atlântico define a região da Costa Verde (Figura 1). 


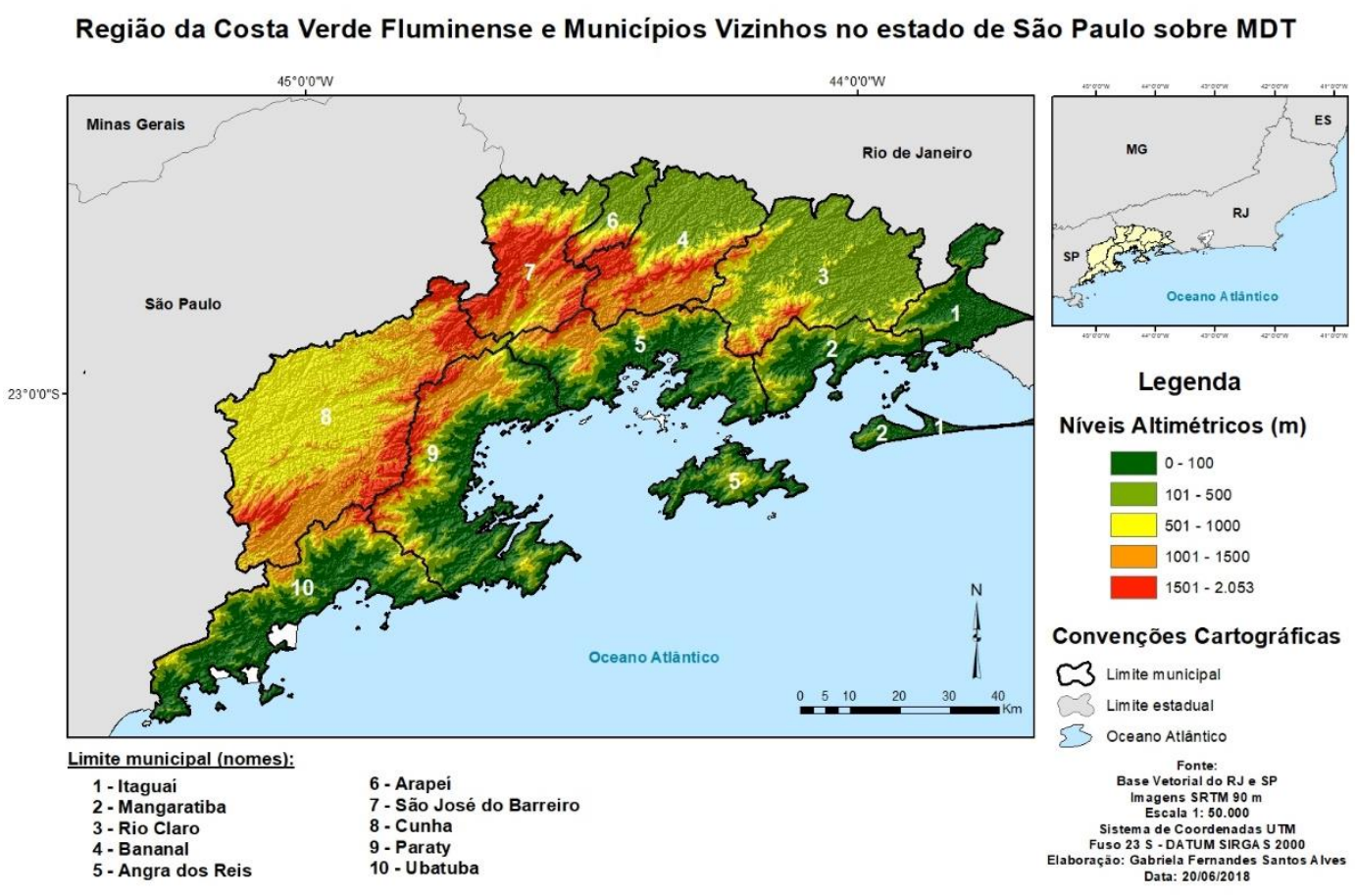

Figura 1. Mapa da Área de Estudo sobre modelo digital do terreno. Fonte: Elaborado por Gabriela Fernandes Santos Alves

Rio Claro, com uma população de pouco mais de 17.000 habitantes (IBGE, 2010), destaca-se pela presença de pequenas e médias indústrias, com ênfase para a indústria de fabricação de calçados e produtos alimentícios, mas a base da economia local é proveniente do comércio e de serviços (RIO CLARO, 2014).

Itaguaí, município que nos últimos anos tem apresentado grande crescimento, desde 2009 passou a integrar a Região Metropolitana do Rio de Janeiro. A chegada da Companhia Siderúrgica do Atlântico (CSA) nas proximidades da cidade, além dos investimentos no Porto de Itaguaí e novos portos privados, passaram a dinamizar a economia da cidade, hoje com mais de 100.000 habitantes (IBGE, 2010).

Mangaratiba, com pouco mais de 35.000 habitantes (IBGE, 2010), e com 73,9\% de sua vegetação preservada, tem o turismo como vocação principal, onde estão localizados grandes condomínios, hotéis e resorts (MANGARATIBA, 2015), embora ainda sofra com a concorrência dos municípios vizinhos mais famosos, como Angra dos Reis e Paraty. Sua economia está baseada principalmente no setor terciário. 
Paraty, famosa pela arquitetura colonial e ruas de pedra, tem se destacado por eventos culturais como a Festa Literária Internacional de Paraty - Flip. Com apenas 37.000 habitantes (IBGE, 2010) e milhares de turistas, o município celebra seus avanços como destino turístico importante. Hoje, junto a Angra dos Reis, Rio de Janeiro, Cabo Frio e Búzios, está entre os principais destinos turísticos do Estado.

Angra dos Reis mantém a pesca e o turismo como atividades econômicas de destaque em suas praias e ilhas. Conta também com grandes investimentos em indústrias de atividades portuárias, de geração de energia - usinas Angra I e Angra II -, e a indústria naval. Estes empreendimentos movimentaram grandes contingentes migratórios durante suas fases de construção, fazendo com que a cidade se expandisse de forma desordenada. Assim, hoje, muitos dos atuais 169.000 habitantes ocupam irregularmente as encostas íngremes e planícies de inundação do município (FARIAS e LOUSADA, 2014).

A Costa Verde fluminense encontra-se na divisa com o estado de São Paulo, fazendo limite com Bananal, Cunha, São José do Barreiro e Ubatuba que são municípios com pequena população e classificados com estâncias pelo governo estadual (Tabela 1).

\begin{tabular}{clccc}
\hline \multirow{2}{*}{ Estado } & \multicolumn{1}{c}{ Município } & População & Área $\left(\mathbf{k m}^{2}\right)$ & $\begin{array}{c}\text { Densidade } \\
\text { Demográfica }\end{array}$ \\
& & & & \\
\hline \multirow{2}{*}{ RJ } & Angra dos Reis & 169.511 & 825,082 & 205,45 \\
& Itaguaí & 109.091 & 274,401 & 395,45 \\
& Mangaratiba & 36.456 & 358,982 & 102,29 \\
& Paraty & 37.533 & 925,392 & 40,57 \\
& Rio Claro & 17.425 & 834,691 & 20,81 \\
& Bananal & 10.223 & 616,427 & 16,58 \\
& Cunha & 21.866 & $1.407,250$ & 15,54 \\
& São José do Barreiro & 4.077 & 570,685 & 7,14 \\
& Ubatuba & 10.223 & 616,417 & 16,58 \\
\hline
\end{tabular}

Tabela 1. Dados municipais sobre População, Área Territorial e Densidade Demográfica. Fonte: Censo Demográfico do IBGE (2010) Elaborado por Heitor Soares de Farias

Estância é um título concedido pelo governo do estado de São Paulo a municípios que apresentam determinados requisitos como: condições de lazer, recreação, recursos naturais e culturais específicos, dispondo de infraestrutura e serviços dimensionados à atividade turística. Os municípios com este 
status recebem aportes financeiros específicos para incentivo ao turismo. Atualmente dos 645 municípios de São Paulo, 70 possuem essa classificação. São 32 estâncias turísticas, 15 estâncias turísticas balneárias, 12 estâncias turísticas climáticas e 11 estâncias turísticas hidrominerais (SÃO PAULO, 2018). Bananal e São José do Barreiro são estâncias turísticas, Cunha é uma estância climática e Ubatuba é uma estância balneária.

Assim, observa-se na região de estudo estágios diferenciados e particularmente aprofundados de degradação do ambiente e das condições de qualidade de vida dos moradores dessas cidades, principalmente nos municípios de Itaguaí e Angra dos Reis, consequência do intenso processo de transformação a que têm passado pelo crescimento de população e densidade demográfica. Angra dos Reis, apesar de possuir uma área territorial maior, tem grande parte de seu território acima da cota de 100 metros, restando poucas planícies confinadas entre o mar e a montanha, que são ocupadas por uma população de maior poder aquisitivo. Quem não pode pagar o preço para morar na planície acaba por ocupar as encostas, áreas mais suscetíveis a deslizamentos, o que torna essa população mais vulnerável a desastres naturais (FARIAS, 2012).

\section{Materiais e Métodos}

Os dados pluviométricos diários foram extraídos dos bancos de dados do Instituto Nacional de Meteorologia (INMET) por meio do Banco de Dados Meteorológicos para Ensino e Pesquisa (BDMEP), da Empresa Brasileira de Pesquisa Agropecuária (EMBRAPA) por meio do portal AGRITEMPO e do National Oceanic and Atmospheric (NOAA), referente ao período de janeiro de 2001 a dezembro de 2016. São doze estações meteorológicas convencionais localizadas nos municípios de Paraty, Angra dos Reis, Mangaratiba, Rio Claro, Bananal e Cunha (Tabela 2).

Este período justifica-se por ser uma série coincidente entre as estações selecionadas na área de estudo, incluindo a ocorrência dos três eventos com grande destaque na mídia pela intensidade e danos causados em Angra dos Reis e adjacências 


\begin{tabular}{|c|c|c|c|c|c|c|c|}
\hline UF & Município & Nome & Código & Latitude & Longitude & Altitude & Operador \\
\hline \multirow{10}{*}{ RJ } & \multirow{3}{*}{$\begin{array}{c}\text { Angra dos } \\
\text { Reis }\end{array}$} & TRMM. 951 & 90022401 & -23.0 & $-44.25^{\circ}$ & 1172 & EMBRAPA \\
\hline & & Bracuhy & 2244149 & -22.94 & $-44.4^{\circ}$ & 70 & NOAA \\
\hline & & V. Mambucaba & 2344016 & -23.03 & $-44.52^{\circ}$ & 0 & NOAA \\
\hline & \multirow[t]{2}{*}{ Mangaratiba } & Marambaia & 9000396 & $-23^{\circ} 03^{\prime}$ & $-43^{\circ} 36^{\prime}$ & 7 & NOAA \\
\hline & & Paraty & 9000542 & $23^{\circ} 13^{\prime} 23.88 "$ & $44^{\circ} 43^{\prime} 36^{\prime} 12^{\prime \prime}$ & 3 & INMET \\
\hline & \multirow[t]{3}{*}{ Paraty } & TRMM.906 & 9002133 & $-23^{\circ} 15^{\prime}$ & $-44^{\circ} 45^{\prime}$ & 395 & NOAA \\
\hline & & TRMM.950 & 9007247 & $-23^{\circ} 00^{\prime}$ & $-44^{\circ} 45^{\prime}$ & 1275 & NOAA \\
\hline & & Trindade & 9000221 & $-23^{\circ} 18^{\prime}$ & $-44^{\circ} 36^{\prime}$ & 835 & NOAA \\
\hline & \multirow{2}{*}{ Rio Claro } & TRMM.997 & 9002440 & $-22^{\circ} 45^{\prime}$ & $-44^{\circ} 15^{\prime}$ & 1219 & NOAA \\
\hline & & TRMM.998 & 9002441 & $-22^{\circ} 45^{\prime}$ & $-44^{\circ} 00^{\prime}$ & 8 & NOAA \\
\hline \multirow{2}{*}{$\mathrm{SP}$} & Bananal & TRMM.996 & 9002439 & $-22^{\circ} 45^{\prime}$ & $-44^{\circ} 30^{\prime}$ & 1332 & NOAA \\
\hline & Cunha & TRMM.949 & 9002400 & $-23^{\circ} 00^{\prime}$ & $-45^{\circ} 00^{\prime}$ & 1175 & NOAA \\
\hline
\end{tabular}

Tabela 2. Estações meteorológicas convencionais utilizadas nesse estudo Fonte: www.mda.gov.br/saf - $1^{0}$ sem 2010.

${ }^{1}$ NOAA, ${ }^{2}$ INMET, ${ }^{3}$ EMBRAPA Organizado por Gabriela Fernandes Santos Alves

A análise das tabelas foi dificultada, pois os dados são disponibilizados segundo o total acumulado a cada dia, impedindo concluir em termos de intensidade de chuva horária, como também, muitas vezes, segmentando em dois dias eventos chuvosos de grande intensidade que iniciam a noite e prolongam-se pela madrugada.

Para a elaboração da distribuição espacial da precipitação foi utilizado o algoritmo interpolador IDW (Inverse Distance Weighting) disponível na extensão Spatial Analyst do Sistema de Informação Geográfica (SIG) ArcGIS 10.1, com o objetivo de avaliar a variabilidade espacial de um determinado fenômeno por meio de dados de um determinado local (JIMENEZ e DOMECQ, 2008).

De acordo com Gardiman Junior et. al. (2012) a utilização de um número maior de estações permite uma melhor representação da situação pluviométrica, uma vez que os mapas gerados com a presença de todas as estações, apresentam maior homogeneidade na representação espacial da chuva média e/ou acumulada anual. Esta superioridade na homogeneidade nos mapas que contém um maior número de estações deve-se ao fato do interpolador possuir um maior conjunto de dados para espacializar.

Sobre esta temática, Akkala et. al. (2010) afirmam que a distribuição espacial dos dados observados, a presença de descontinuidades significativas e a densidade de estações na área interpolada podem vir a 
interferir nos resultados de precipitação obtidos pelos métodos de interpolação. Diante dessas prerrogativas se fez necessário adicionar estações meteorológicas de municípios vizinhos para que a aplicação do interpolador fosse eficiente, justificando-se a utilização de outros municípios para além daqueles integrantes da Costa Verde fluminense. Para isso adicionou-se dados de mais estações meteorológicas convencionais distribuídas ao longo do estado do Rio de Janeiro e São Paulo, totalizando doze pontos, conforme tabela 2.

O interpolador IDW assume que a área de influência de cada amostra diminui com o aumento da distância em relação a outra amostra. Durante a interpolação, a ponderação diminui conforme aumenta a distância entre a amostra e o nó da grade a serem estimados, assim os pontos amostrados, próximos ao nó a ser estimado, recebem peso maior do que os pontos amostrados de localização mais distantes. Ao calcular o valor de um nó, a soma de todos os pesos atribuídos aos pontos amostrados vizinhos é igual a 1,0, ou seja, é atribuído um peso proporcional à contribuição de cada ponto vizinho (LANDIM, 2000).

Assim, com uma grade de interpolação com cinquenta metros de resolução, foram criados quatro mapas para a análise espacial das chuvas. Um com a precipitação média no período de 2001 a 2016 , e outros três mapas com valores acumulados de chuva nos dias de ocorrência dos eventos extremos e 0 dia seguinte ao início das tempestades. Isso porque segundo as manchetes jornalísticas que cobriram os casos, as chuvas iniciaram à noite e se prolongaram pela madrugada. Foram utilizados os totais dos dias 9 e 10 de dezembro de 2002, 31 de dezembro de 2009 e $1^{\circ}$ de janeiro de 2010, e 3 e 4 de janeiro de 2013.

Juntamente com os mapas foram criadas tabelas com dados diários de chuvas das doze estações. 0 objetivo foi verificar os registros de pluviosidades nas estações e acompanhar a evolução das tempestades nos três eventos marcantes. Para a construção das tabelas foram escolhidos os dias 7 a 14 de dezembro de 2002; 27 de dezembro de 2009 a 03 de janeiro de 2010; e, 27 de dezembro de 2012 a 05 de janeiro de 2013, destacando os dias mais chuvosos no período entre o início e o fim da chuva que desencadeou cada um dos eventos na região. 
Para embasar as análises foram utilizadas imagens de satélite e análise sinótica do Centro de Previsão de Tempo e Estudos Climáticos (CPTEC) que, no entanto, somente estão disponíveis a partir do ano de 2008, sendo necessária a utilização da carta sinótica da Marinha Brasileira para análise do evento de 2002.

\section{Resultados}

Utilizando-se do software Microsoft Excel, os dados pluviométricos das estações foram organizados em tabelas. Na tabela 3 está o total anual de chuvas, de onde foram extraídos a média e o desvio padrão. Destacou-se em azul os anos mais chuvosos, aqueles que apresentaram totais pluviométricos superiores ao somatório da média com o desvio padrão; e em vermelho os anos mais secos, aqueles que apresentaram totais pluviométricos inferiores à subtração do desvio padrão na média. Assim, foi possível observar que não há comportamento que seja unânime entre as localidades em cada ano, mas há uma tendência à concentração.

\begin{tabular}{|c|c|c|c|c|c|c|c|c|c|c|c|c|}
\hline $\begin{array}{l}\text { Chuva } \\
(\mathrm{mm})\end{array}$ & $\begin{array}{c}\text { Trindade } \\
1\end{array}$ & $\begin{array}{c}\text { Paraty } \\
906^{1}\end{array}$ & $\begin{array}{c}\text { Paraty } \\
\text { INMET }^{2}\end{array}$ & $\begin{array}{c}\text { Paraty } \\
950^{1}\end{array}$ & Cunha $^{1}$ & $\begin{array}{c}\text { Bananal } \\
1\end{array}$ & $\begin{array}{c}\text { Rio } \\
\text { Claro } \\
997^{1}\end{array}$ & $\begin{array}{c}\text { Rio } \\
\text { Claro } \\
998^{1}\end{array}$ & Mambucaba $^{1}$ & $\begin{array}{c}\text { Bracuhy } \\
1\end{array}$ & $\begin{array}{c}\text { Angra } \\
\text { TRMM. } \\
951^{3}\end{array}$ & $\begin{array}{c}\text { Mangaratib } \\
\text { a } \\
\text { Marambaia }^{1}\end{array}$ \\
\hline 2001 & 1132,89 & $\begin{array}{c}1132,8 \\
9\end{array}$ & 1132,89 & 1302,75 & $\begin{array}{c}1481,6 \\
7\end{array}$ & 1721,67 & $\begin{array}{c}1565,6 \\
1\end{array}$ & 1558,8 & 1688,9 & 2041,4 & 1163,7 & 1307,58 \\
\hline 2002 & 866,79 & 886,79 & 866,79 & $\begin{array}{c}1164,5 \\
4\end{array}$ & 1253,37 & 1610,13 & 1423,77 & $\begin{array}{c}1249,6 \\
2\end{array}$ & 2066,2 & 2538,9 & 981 & 1322,55 \\
\hline 2003 & 1910,36 & 878,16 & 878,16 & $\begin{array}{c}1181,9 \\
4\end{array}$ & 1222,41 & 1308,81 & 1254,3 & 1247,13 & 2091,2 & 2453,77 & 967,56 & 1231,14 \\
\hline 2004 & 1059,37 & 948,51 & 948,51 & 1138,5 & 1279,47 & 1570,83 & $\begin{array}{c}1481,4 \\
9\end{array}$ & $\begin{array}{c}1173,8 \\
1\end{array}$ & 2576,2 & 2296,5 & $\begin{array}{c}1118,8 \\
2\end{array}$ & 1263,3 \\
\hline 2005 & 800,99 & 813,36 & 813,36 & 1033,02 & 1221 & 1373,04 & 1233,21 & 1172,91 & 2549 & 2661,95 & 874,35 & 946,26 \\
\hline 2006 & 1402,93 & 993,93 & 1096,35 & $\begin{array}{c}1398,4 \\
8\end{array}$ & 1324,5 & 1690,92 & 1795,44 & $\begin{array}{c}1625,5 \\
5\end{array}$ & 1995,4 & 2060,4 & 1332,51 & 1149,9 \\
\hline 2007 & 1107,92 & 895,95 & 1069,28 & 988,71 & 1169,1 & 1229,79 & $\begin{array}{c}1098,8 \\
4\end{array}$ & $\begin{array}{c}1202,7 \\
6\end{array}$ & 1844,1 & 1592,6 & 869,91 & 888,59 \\
\hline 2008 & 1690,8 & 1133,79 & 1766,6 & 1727,91 & $\begin{array}{c}1858,1 \\
4\end{array}$ & 1740,03 & $\begin{array}{c}1696,8 \\
3\end{array}$ & $\begin{array}{c}1656,5 \\
4\end{array}$ & 2476,8 & 2209 & $\begin{array}{c}1546,6 \\
5\end{array}$ & 1438,05 \\
\hline 2009 & 1368,53 & $\begin{array}{c}1311,8 \\
7\end{array}$ & 998,6 & $\begin{array}{c}1672,8 \\
3\end{array}$ & $\begin{array}{c}1840,4 \\
1\end{array}$ & 1970,34 & $\begin{array}{c}1804,2 \\
3\end{array}$ & $\begin{array}{c}1735,8 \\
3\end{array}$ & 2866,4 & 2764,2 & $\begin{array}{c}1462,8 \\
9\end{array}$ & 774,29 \\
\hline 2010 & 1323,87 & $\begin{array}{c}1323,8 \\
7\end{array}$ & 1316 & $\begin{array}{c}1670,6 \\
1\end{array}$ & $\begin{array}{c}1609,3 \\
5\end{array}$ & 1846,5 & $\begin{array}{c}1846,1 \\
7\end{array}$ & 1647 & 3018,6 & 3224,5 & $\begin{array}{c}1497,6 \\
3\end{array}$ & 1669,4 \\
\hline 2011 & 1049,94 & 1049,94 & 1824,42 & $\begin{array}{c}1336,5 \\
9\end{array}$ & 1518,3 & 1585,41 & 1392 & 1293,03 & 2508,7 & 2283,5 & $\begin{array}{c}1103,7 \\
6\end{array}$ & 1076,47 \\
\hline 2012 & 1081,8 & 1081,8 & 913,37 & 1401,3 & 1443 & 1511,85 & 1559,43 & $\begin{array}{c}1627,1 \\
7\end{array}$ & 1656,1 & 1580,07 & 1207,05 & 999,15 \\
\hline 2013 & 1282,53 & $\begin{array}{c}1282,5 \\
3\end{array}$ & 1459,91 & $\begin{array}{c}1613,0 \\
1\end{array}$ & $\begin{array}{c}1748,3 \\
7\end{array}$ & 1748,64 & $\begin{array}{c}1628,8 \\
8\end{array}$ & $\begin{array}{c}1760,3 \\
7\end{array}$ & 2827 & 2891,1 & $\begin{array}{c}1376,0 \\
1\end{array}$ & 1022,24 \\
\hline 2014 & 668,91 & 668,91 & 1161,6 & 962,25 & $\begin{array}{c}1110,6 \\
6\end{array}$ & 1360,68 & 1152,51 & 1012,17 & 1564,5 & 1472,7 & 900,12 & 631,58 \\
\hline 2015 & 1173,75 & 1173,75 & 1508,83 & 1439,1 & 1712,19 & 1899,48 & $\begin{array}{c}1763,9 \\
4\end{array}$ & $\begin{array}{c}1766,6 \\
1\end{array}$ & 2324,6 & 1932,7 & 1251,42 & 924,6 \\
\hline
\end{tabular}




\begin{tabular}{|c|c|c|c|c|c|c|c|c|c|c|c|c|}
\hline 2016 & 1154,95 & $\begin{array}{c}1167,6 \\
1\end{array}$ & 1619,8 & $\begin{array}{c}1385,8 \\
7\end{array}$ & $\begin{array}{c}1587,7 \\
4\end{array}$ & 1638,16 & $\begin{array}{c}1599,8 \\
7\end{array}$ & 1753,22 & 2000,7 & 2212,7 & 1294,44 & 837,9 \\
\hline Media & 1192,27 & $\begin{array}{c}1046,4 \\
8\end{array}$ & 1210,9 & $\begin{array}{c}1338,5 \\
9\end{array}$ & $\begin{array}{c}1461,2 \\
3\end{array}$ & 1612,89 & $\begin{array}{c}1518,5 \\
3\end{array}$ & $\begin{array}{c}1467,6 \\
6\end{array}$ & 2253,4 & 2263,5 & $\begin{array}{c}1184,2 \\
4\end{array}$ & 1092,69 \\
\hline $\begin{array}{l}\text { Desvio } \\
\text { Padrão }\end{array}$ & 302,13 & 183,04 & 320,7 & 240,09 & 238,04 & 207,78 & 232,92 & 254,04 & 440,98 & 473,58 & 217,68 & 260,61 \\
\hline
\end{tabular}

Tabela 3. Total anual de chuvas, Média e Desvio Padrão, com destaque para anos mais chuvosos e mais secos na região da Costa Verde, no período de 2001 a 2016. Fonte: ${ }^{1}$ NOAA, ${ }^{2}$ INMET, ${ }^{3}$ EMBRAPA Organizado por Heitor Soares de Farias.

Os anos 2008, 2009, 2010 e 2013 destacaram-se como os mais chuvosos, ao passo que 2005 e 2014 destacaram-se como os mais secos. Com especial atenção aos anos dos eventos catastróficos, 2010 e 2013 aparecem como anos chuvosos, com totais acumulados acentuadamente acima da média, ficando o ano de 2002 dentro da normalidade.

O ano de 2014 foi um dos mais secos para onze das doze estações meteorológicas. Dessas onze estações, para nove foi realmente o ano mais seco. Neste ano, nas estações Trindade, Paraty 906 e Mangaratiba, que estão nos limites oeste e leste da área de estudo, respectivamente, foram registrados os menores totais de chuva, acumulando pouco mais de $600 \mathrm{~mm}$, cerca da metade da média do período. Apenas a estação Paraty INMET apresentou registros muito próximos do habitual e não esteve entre as mais secas. Este fato pode ser explicado pela ocorrência de um bloqueio atmosférico em janeiro e fevereiro deste ano de 2014, anormal para este período do ano (LUIZ SILVA et al., 2015)

O ano de 2009 foi chuvoso para nove das doze estações meteorológicas. Neste ano, as estações que apresentaram menores totais de precipitação, onde não se caracterizaram como um ano chuvoso, foram Trindade e Paraty INMET à oeste, e Mangaratiba à leste da área de estudo, ou seja, choveu mais na área central - municípios de Angra dos Reis e Rio Claro. Em Mangaratiba o ano de 2009 foi o segundo mais seco do período estudado, ficando atrás apenas de 2014.

Os maiores totais de chuvas entre todas as estações estão no município de Angra dos Reis, nas estações Bracuhy $(3224,50 \mathrm{~mm})$ e Mambucaba (3018,60 mm), no ano de 2009. No período analisado, somente nestas duas estações meteorológicas foram registradas precipitações acumuladas superiores a $2000 \mathrm{~mm}$. No ano de 2014, o "mais seco" destas estações para o período, Bracuhy (1472,7 mm) e Mambucaba $(1564,5 \mathrm{~mm})$, os totais acumulados são superiores à média de cada uma das demais estações. 
Esses resultados mostram que há forte concentração da precipitação nestas duas estações localizadas no município de Angra dos Reis - Bracuhy e Mambucaba, enquanto que os extremos oeste e leste da área de estudo - Paraty e Mangaratiba/Marambaia apresentam menores totais pluviométricos do período. Isto fica ainda mais evidente quando a precipitação média do período 2001 a 2016 é spacializada (Figura 2).

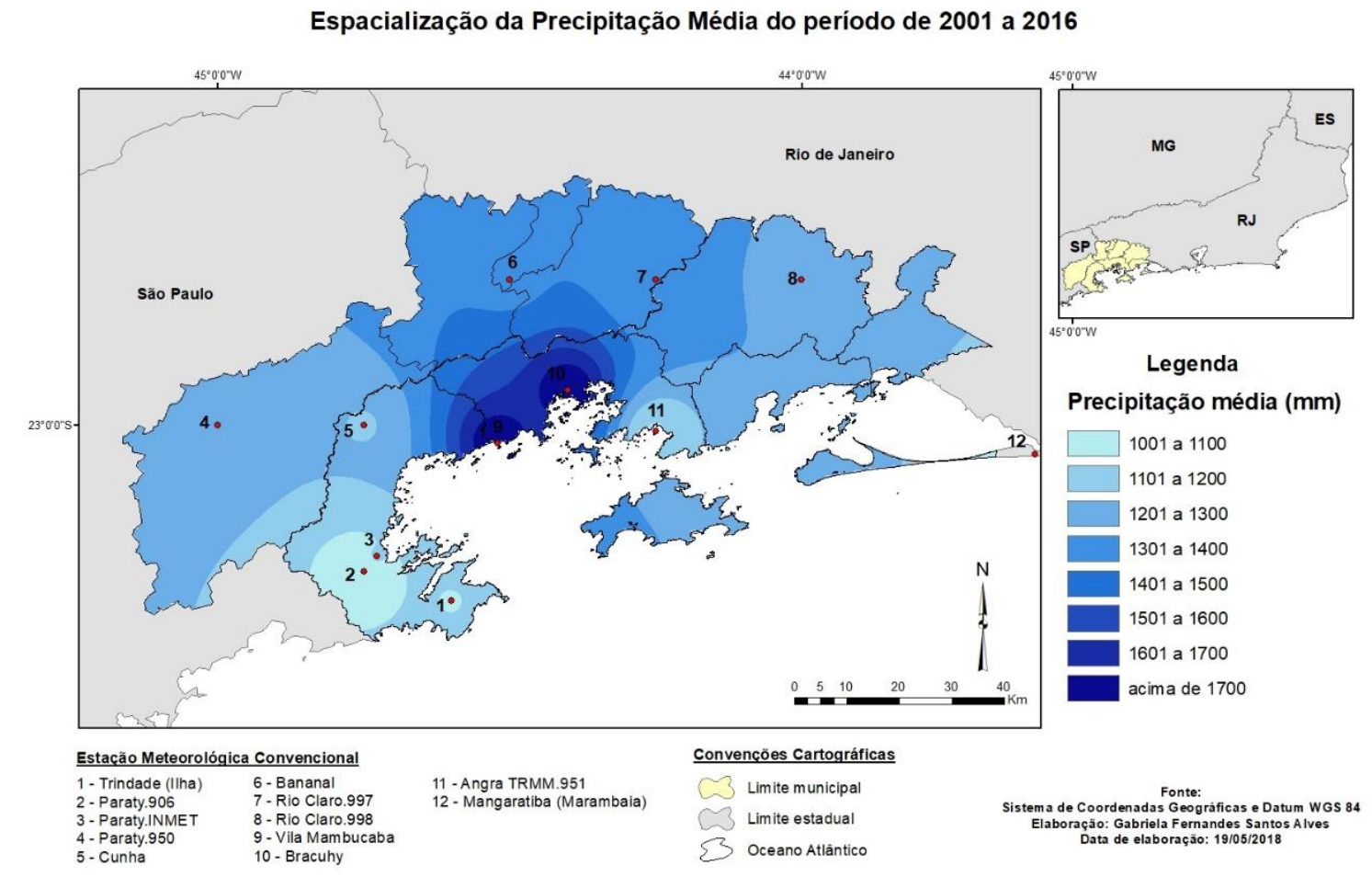

Figura 2. Espacialização da Precipitação Média no período de 2001 a 2016 . Fonte: Elaborado por Gabriela Fernandes Santos Alves

Na tabela 4 estão os registros máximos de chuva em 24 horas, em cada ano, junto com as médias dos registros máximos e os respectivos desvios padrão, no período de 2001 a 2016. Em azul claro foram destacados os registros máximo superiores à média das máximas no período; em azul escuro foram destacados os registros máximos superiores à soma das médias das máximas com o desvio padrão.

Nos anos de 2002; 2003; 2008; 2009; 2010; 2013; 2015 e 2016 foram registrados eventos pluviométricos elevados. Com especial atenção aos anos dos eventos catastróficos, 2002, 2010 e 2013, apenas as estações meteorológicas de Cunha e Bracuhy apresentaram registros máximos muito acima da média nos três anos. 
Metade das estações, seis em doze, apresentaram o registro máximo da série no ano de 2010 (Bananal; Trindade; Paraty 905; Paraty 906; Rio Claro 997 e Rio Claro 998), e outras três estações apresentaram registros muito elevados (Cunha; Bracuhy e Mangaratiba) também neste ano. Outros registros máximos ocorreram em 2006 na estação Mangaratiba/Marambaia, em 2008 na estação Angra TRMM.951, em 2011 na estação Paraty INMET, e em 2013 nas estações Cunha, Mambucaba e Bracuhy. No ano de 2013 foram registradas as maiores concentrações de chuva em 24 horas: em Bracuhy foram 224,3 mm e Mambucaba 318,9 mm.

\begin{tabular}{|c|c|c|c|c|c|c|c|c|c|c|c|c|}
\hline $\begin{array}{c}\text { Chuva } \\
\text { (mm) }\end{array}$ & $\underset{1}{\text { Trindade }}$ & $\begin{array}{c}\text { Paraty } \\
\text { 906 }^{1}\end{array}$ & $\begin{array}{c}\text { Paraty } \\
\text { INMET }^{2}\end{array}$ & $\begin{array}{c}\text { Paraty } \\
9^{550}\end{array}$ & Cunha $^{1}$ & Bananal $^{1}$ & $\begin{array}{l}\text { Rio } \\
\text { Claro } \\
9971\end{array}$ & $\begin{array}{c}\text { Rio } \\
\text { Claro } \\
\text { 9981 }^{1}\end{array}$ & Mambucaba $^{1}$ & $\begin{array}{c}\text { Bracuhy } \\
1\end{array}$ & $\begin{array}{c}\text { Angra } \\
\text { TRMM. } \\
\mathbf{9 5 1}^{3}\end{array}$ & $\begin{array}{c}\text { Mangaratib } \\
\text { a } \\
\text { Marambaia }^{1}\end{array}$ \\
\hline 2001 & 58,5 & 58,5 & 58,5 & 67,14 & 67,65 & 79,14 & 65,4 & 82,17 & 85 & 126,9 & 76,74 & 68,73 \\
\hline 2002 & 63,18 & 63,18 & 63,18 & 59,55 & 82,71 & 63,93 & 69,81 & 76,26 & 175,5 & 181,3 & 49,35 & 69,54 \\
\hline 2003 & 181 & 64,02 & 64,02 & 57,9 & 67,59 & 93,3 & 65,88 & 90,3 & 216 & 152,6 & 58,65 & 75,15 \\
\hline 2004 & 121,6 & 42,27 & 42,27 & 52,53 & 54,81 & 74,4 & 54,87 & 56,1 & 104,5 & 151,3 & 64,23 & 78,06 \\
\hline 2005 & 83,43 & 83,43 & 83,43 & 49,41 & 74,61 & 62,1 & 75,99 & 66,96 & 115,7 & 102 & 49,56 & 66,24 \\
\hline 2006 & 85 & 52,14 & 52,14 & 66,84 & 59,4 & 72,3 & 75,96 & 73,59 & 98,2 & 114,1 & 72,42 & 126,87 \\
\hline 2007 & 65 & 54,84 & 57,4 & 66,54 & 73,17 & 62,55 & 83,43 & 97,62 & 177,3 & 154,8 & 67,89 & 56,2 \\
\hline 2008 & 167 & 51,27 & 63,2 & 95,16 & 60,3 & 93,27 & 105,15 & 80,79 & 115,1 & 158 & 133,47 & 92,85 \\
\hline 2009 & 80,25 & 80,25 & 167 & 73,53 & 88,23 & 95,67 & 82,38 & 109,77 & 216,5 & 114,1 & 85,5 & 105 \\
\hline 2010 & 189,09 & $\begin{array}{c}189,0 \\
9\end{array}$ & 67,2 & 128,82 & 84,42 & 101,79 & $\begin{array}{c}113,6 \\
4\end{array}$ & $\begin{array}{c}146,8 \\
8\end{array}$ & 196,5 & 197,5 & 92,67 & 113,6 \\
\hline 2011 & 51,45 & 51,45 & 170,6 & 70,74 & 51,15 & 73,2 & 66,3 & 90,9 & 177,8 & 135,2 & 54,24 & 50,4 \\
\hline 2012 & 43,14 & 43,14 & 107,4 & 67,44 & 56,31 & 68,43 & 66,69 & 70,74 & 76 & 73,1 & 51,63 & 44,8 \\
\hline 2013 & 62,85 & 62,85 & 56,7 & 64,98 & 88,35 & 59,64 & 59,85 & 70,95 & 318,9 & 224,3 & 71,25 & 63,78 \\
\hline 2014 & 61,29 & 61,29 & 46 & 63,57 & 69 & 57,96 & 73,71 & 100,17 & 67,5 & 147,1 & 64,11 & 67,4 \\
\hline 2015 & 65,25 & 65,25 & 104,6 & 52,08 & 74,49 & 73,17 & 82,56 & $\begin{array}{c}120,9 \\
6\end{array}$ & 122,6 & 75,6 & 70,14 & 120,4 \\
\hline 2016 & 88,98 & 88,98 & 103,8 & 110,49 & 77,85 & 98,64 & 99,21 & 115,8 & 124,3 & 94 & 92,04 & 54 \\
\hline $\begin{array}{c}\text { Media } \\
\text { das }\end{array}$ & 91,69 & 69,5 & 81,72 & 71,67 & 70,63 & 76,84 & 77,55 & 90,62 & 149,21 & 137,62 & 72,12 & 78,31 \\
\hline Máximas & & & & & & & & & & & & \\
\hline $\begin{array}{l}\text { Desvio } \\
\text { Padrão }\end{array}$ & 47,14 & 34,57 & 39,6 & 21,77 & 11,94 & 14,97 & 16,44 & 23,7 & 66,68 & 42,13 & 21,42 & 25,74 \\
\hline
\end{tabular}

Tabela 4. Registros máximos de chuva em 24 horas, em cada ano, com destaque para os registros mais elevados da série, no período de 2001 a 2016 . Fonte: ${ }^{1}$ NOAA, ${ }^{2}$ INMET, ${ }^{3}$ EMBRAPA Organizado por Heitor Soares de Farias

Após uma visão geral sobre as médias e registros máximos sobre as estações meteorológicas, dar-se-á destaque para os eventos extremos de pluviosidade com efeitos sobre a desorganização do espaço de Angra dos Reis, ocorridos nos anos de 2002, 2009/2010 e 2013.

\section{Evento de 2013}


Na última semana do ano de 2012 e na primeira de 2013 choveu bastante em toda a região. No dia 03 de janeiro foram registrados os maiores totais na região, principalmente em Angra dos Reis: em Mambucaba, o registro máximo de 318,9 mm de chuva, sendo que continuou chovendo no dia seguinte (04/01) quando foram registrados mais $127,8 \mathrm{~mm}$. Neste evento concentrado precipitou mais de 446 mm em 48 horas, um quinto do esperado para todo o ano em Mambucaba, segundo a média deste período (Tabela 5).

Em Bracuhy foi registrado 224,3 $\mathrm{mm}$ no dia 3 de janeiro, sendo que continuou chovendo no dia seguinte (04/01) quando foram registrados mais $111 \mathrm{~mm}$, totalizando mais de $335 \mathrm{~mm}$ em 48 horas. Já a estação TRMM.951, localizada no bairro Jacuecanga, zona leste do município de Angra dos Reis, embora também muito próxima, registrou chuvas muito menos intensas nos dias 3 e 4 de janeiro, quando precipitaram 71,25 mm e 47,37 mm, respectivamente. Um total de mais de $118 \mathrm{~mm}$ em 48 horas que, no entanto, é muito inferior ao registrado em Mambucaba (446 mm) e Bracuhy (335 mm).

\begin{tabular}{|c|c|c|c|c|c|c|c|c|c|c|c|c|c|}
\hline & Dia & $\underset{1}{\text { Trindade }}$ & $\begin{array}{c}\text { Parat } \\
\text { y } 906^{1}\end{array}$ & $\begin{array}{c}\text { Paraty } \\
\text { INMET }^{2}\end{array}$ & $\begin{array}{c}\text { Parat } \\
\text { y } 950^{1}\end{array}$ & Cunha $^{1}$ & Bananal $^{1}$ & $\begin{array}{c}\text { Rio } \\
\text { Claro } \\
9971\end{array}$ & $\begin{array}{c}\text { Rio } \\
\text { Claro } \\
\mathbf{9 9 8}^{1}\end{array}$ & Mambucaba $^{1}$ & $\begin{array}{c}\text { Bracuhy } \\
1\end{array}$ & $\begin{array}{c}\text { Angra } \\
\text { TRMM } \\
951^{3}\end{array}$ & $\begin{array}{c}\text { Mangaratib } \\
\text { a } \\
\text { Marambaia }^{1}\end{array}$ \\
\hline \multirow{5}{*}{2012} & $\begin{array}{c}27 / \mathrm{de} \\
\mathrm{z}\end{array}$ & 3 & 3 & 0 & 0 & 13,56 & 0 & 0 & 0 & 0 & 0 & 0 & 0 \\
\hline & $\begin{array}{c}28 / \mathrm{de} \\
\mathrm{z}\end{array}$ & 14.76 & 14.76 & 14.76 & 67.44 & 31.02 & 41.34 & 13.74 & 1.38 & 1.6 & 0 & 28.59 & 2.97 \\
\hline & $\begin{array}{c}29 / \mathrm{de} \\
\mathrm{z}\end{array}$ & 14.76 & 14.76 & 0 & 4.23 & 17.85 & 0 & 0 & 0 & 0 & 17.2 & 0 & 3 \\
\hline & $\begin{array}{c}30 / \mathrm{de} \\
\mathrm{z}\end{array}$ & 36.45 & 36.45 & 0 & 34.56 & 37.89 & 19.89 & $\begin{array}{c}66.6 \\
9\end{array}$ & 7.71 & 5.1 & 31.2 & 10.5 & 0 \\
\hline & $\begin{array}{c}31 / \mathrm{de} \\
\mathrm{z}\end{array}$ & 16.53 & 16.53 & 0 & 12.81 & 34.38 & 20.79 & 17.25 & 22.53 & 8 & 26.5 & 8.85 & 2.2 \\
\hline \multirow{5}{*}{2013} & $01 /$ jan & 2.25 & 2.25 & 0 & 1.2 & 1.71 & 13.5 & 4.29 & 0 & 13 & 2.4 & 2.79 & 0 \\
\hline & 02/jan & 10.92 & 10.92 & 10.92 & 12.33 & 40.71 & 1.2 & 0 & 0 & 13.2 & 9.5 & 0 & 0 \\
\hline & 03/jan & 56.7 & 56.7 & 56.7 & 34.14 & 21.3 & 19.47 & $\begin{array}{c}26.6 \\
1\end{array}$ & 35.13 & 318.9 & 224.3 & 71.25 & 25.8 \\
\hline & $04 /$ jan & 1.53 & 1.53 & 1.53 & 2.82 & 1.32 & 11.85 & 11.94 & 23.55 & 127.8 & 111 & 47.37 & 16.62 \\
\hline & 05/jan & 6.36 & 6.36 & 0 & 11.04 & 15.99 & 2.13 & 1.74 & 2.79 & 1.5 & 1.2 & 2.55 & 0 \\
\hline
\end{tabular}

Tabela 5. Registro de Chuva nas Estações Meteorológicas - Evento de 2013. Fonte: ${ }^{1}$ NOAA, ${ }^{2}$ INMET, ${ }^{3}$ EMBRAPA Organizado por Gabriela Fernandes Santos e Heitor Soares de Farias

O motivador para esse evento concentrado pode ser entendido a partir da análise da carta sinótica, onde foi observada a presença de um sistema frontal estacionário atuando desde o nordeste do Paraná, 
passando pelo litoral norte de São Paulo e sul do Rio de Janeiro, prosseguindo para o oceano atlântico. A variação dos índices pluviométricos acompanhou o enfraquecimento do sistema frontal (figura 3).

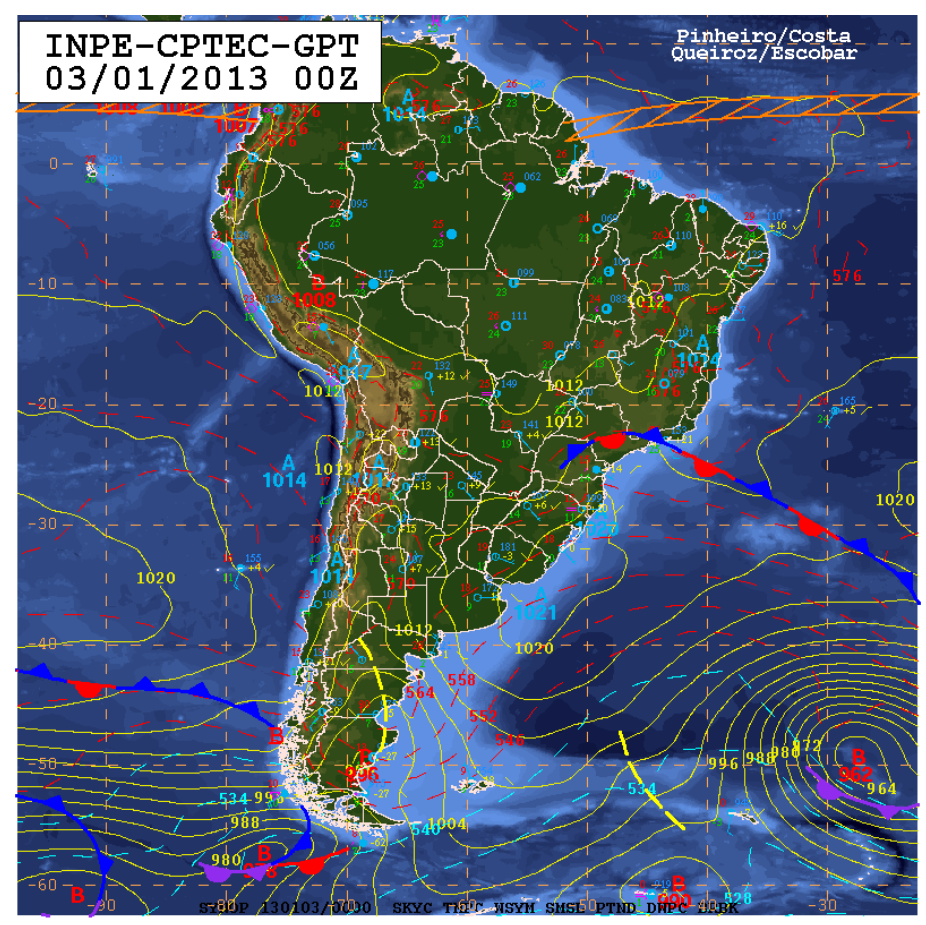

Figura 3. Carta Sinótica do dia 03/01/2013. Fonte: CPTEC/INPE

A Figura 4 apresenta a espacialização da precipitação acumulada nos dias 3 e 4 de janeiro de 2013. Observa-se que este evento, que causou perdas materiais em bairros da zona oeste de Angra dos Reis, foi mais intenso sobre este município do que nos demais, principalmente nas áreas do Parque Mambucaba e Bracuhy, como destacou a manchete jornalística mencionada anteriormente. Mangaratiba também esteve sob impacto de uma chuva forte, mas as demais localidades não foram expressivamente influenciadas. 


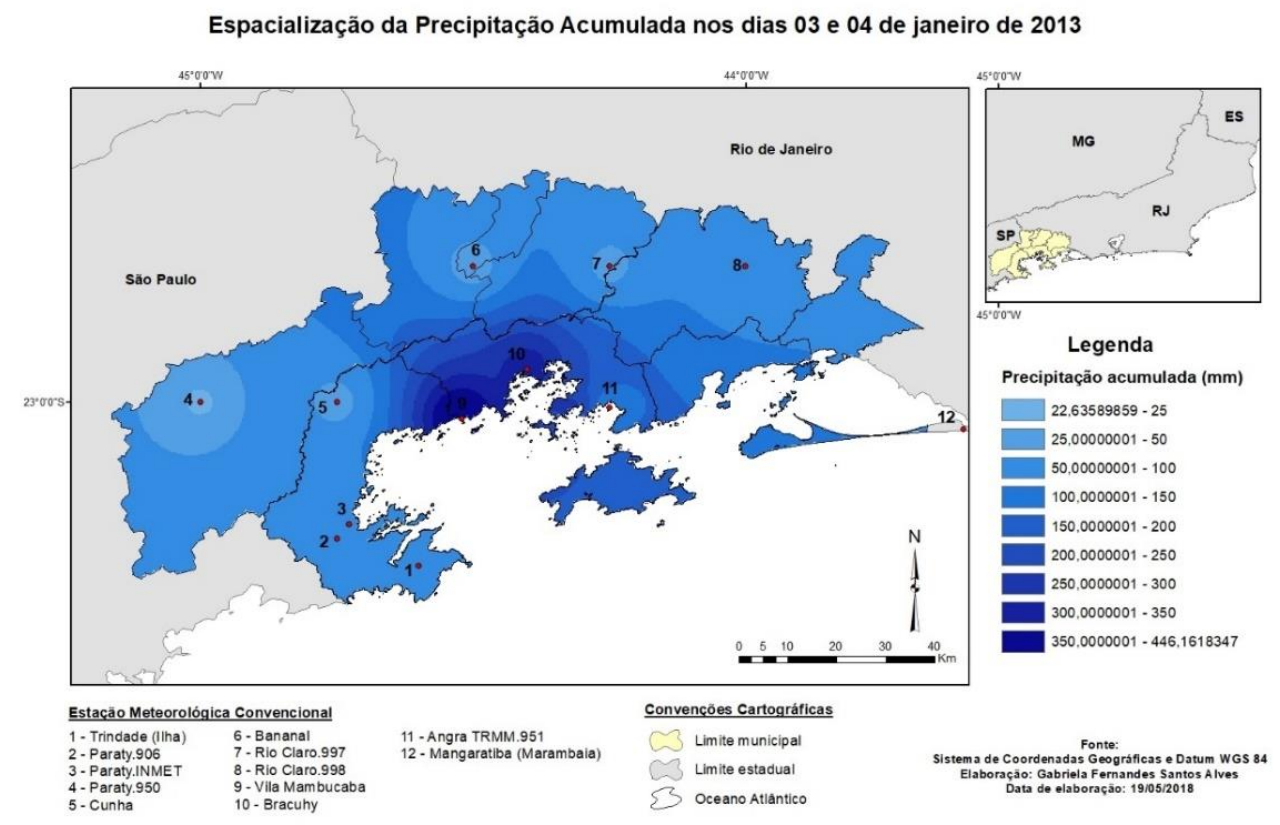

Figura 4. Espacialização da Precipitação Acumulada nos dias 3 e 4 de janeiro de 2013. Fonte: Elaborado por Gabriela Evento de 2009/2010 Fernandes Santos Alves

Como observado na tabela 3, o ano de 2010 foi o que apresentou metade das estações com registro máximo de pluviosidade no período analisado. Em Bracuhy, este ano teve o segundo registro mais elevado de sua série, mas o mais intenso entre as estações em 2010, quando choveu 197,5 mm no dia $1^{0}$ de janeiro. No entanto, no dia anterior já havia chovido 109,7 mm, totalizando mais de $307 \mathrm{~mm}$ em 48 horas (Tabela 6).

Mais uma vez observa-se que o evento mais intenso foi precedido por uma semana de muita chuva que iniciou no dia 28 de dezembro de 2009, não só em Angra dos Reis, onde foram registrados os maiores totais, mas em toda a região. Em Mambucaba, o segundo maior registro foi neste dia $1^{0}$ de janeiro de $2010(196,5 \mathrm{~mm})$, mas a chuva mais intensa iniciou no dia anterior (31/12/2009) com 85,6 mm, totalizando mais de $280 \mathrm{~mm}$ de chuva em 48 horas. Desde o dia 28 de dezembro foram 383,5 mm em 5 dias.

Em Jacuecanga, (Angra TRMM.951) começou a chover de forma mais intensa no dia 31 de dezembro de $2009(78,3 \mathrm{~mm})$ até o dia $1^{\circ}$ de janeiro $(42,36 \mathrm{~mm})$, somando mais de $120 \mathrm{~mm}$ em 48 horas. Desde o dia 28 de dezembro foram $230,4 \mathrm{~mm}$ em 5 dias. 


\begin{tabular}{|c|c|c|c|c|c|c|c|c|c|c|c|c|c|}
\hline & Dia & $\underset{1}{\text { Trindade }}$ & $\begin{array}{c}\text { Paraty } \\
\text { 906 }^{1}\end{array}$ & $\begin{array}{c}\text { Paraty } \\
\text { INMET }^{2}\end{array}$ & $\begin{array}{c}\text { Paraty } \\
9550^{1}\end{array}$ & Cunha $^{1}$ & Bananal $^{1}$ & $\begin{array}{c}\text { Rio } \\
\text { Claro } \\
\mathbf{9 9 7 1} \\
\end{array}$ & $\begin{array}{c}\text { Rio } \\
\text { Claro } \\
\text { 998 }^{1} \\
\end{array}$ & Mambucaba $^{1}$ & $\begin{array}{c}\text { Bracuhy } \\
1\end{array}$ & $\begin{array}{c}\text { Angra } \\
\text { TRMM } \\
\mathbf{9 5 1}^{3}\end{array}$ & $\begin{array}{c}\text { Mangaratib } \\
\text { a } \\
\text { Marambaia }^{1}\end{array}$ \\
\hline \multirow{5}{*}{2009} & $\begin{array}{c}27 / \mathrm{de} \\
\mathrm{z}\end{array}$ & 0 & 0 & 0 & 0 & 0 & 0 & 0 & 1,05 & 0,3 & 0 & 0 & 0 \\
\hline & $\begin{array}{c}28 / \mathrm{de} \\
\mathrm{z}\end{array}$ & 37.68 & 37.68 & 0 & 49.41 & 76.17 & 62.16 & $\begin{array}{c}82.3 \\
8\end{array}$ & $\begin{array}{c}66.7 \\
8\end{array}$ & 59.7 & 33.6 & 85.5 & 14,2 \\
\hline & $\begin{array}{c}29 / \mathrm{de} \\
\mathrm{z}\end{array}$ & 52.17 & 52.17 & 0 & 38.79 & 19.98 & 43.35 & 37.29 & 19.47 & 38.5 & 20 & 19.38 & 5,4 \\
\hline & $\begin{array}{c}30 / \mathrm{de} \\
\mathrm{z}\end{array}$ & 0 & 0 & 0 & 3.03 & 3.66 & 1.59 & 1.41 & 5.76 & 5 & 0.8 & 4.86 & 40,6 \\
\hline & $\begin{array}{c}31 / \mathrm{de} \\
\mathrm{z}\end{array}$ & 80.25 & 80.25 & 0 & 65.19 & 38.46 & 56.19 & $\begin{array}{c}42.1 \\
8\end{array}$ & $\begin{array}{c}55.0 \\
8\end{array}$ & 85.6 & 109.7 & 78.3 & 62,2 \\
\hline \multirow{3}{*}{2010} & $01 /$ jan & 189.09 & $\begin{array}{c}189.0 \\
9\end{array}$ & 0 & $\begin{array}{c}128.8 \\
2\end{array}$ & 84.42 & 71.94 & $\begin{array}{c}18.6 \\
9\end{array}$ & 8.28 & 196.5 & 197.5 & 42.36 & 0 \\
\hline & $02 /$ jan & 12.24 & 12.24 & 0 & 2.88 & 7.98 & 1.62 & 0 & 0.93 & 5.6 & 0 & 1.35 & 0 \\
\hline & 03/jan & 0 & 0 & 0 & 0 & 0 & 0 & 0 & 0 & 0 & 0 & 0 & 0 \\
\hline
\end{tabular}

Tabela 6. Registro de Chuva nas Estações Meteorológicas - Evento de 2009/10. Fonte: ${ }^{1}$ NOAA, ${ }^{2}$ INMET, ${ }^{3}$ EMBRAPA Organizado por Gabriela Fernandes Santos e Heitor Soares de Farias

Em Paraty foram registrados valores idênticos em duas das estações (Trindade e Paraty 906) nos dias 31 de dezembro $(80,25 \mathrm{~mm})$ e $1^{0}$ de janeiro $(189,09 \mathrm{~mm})$, totalizando $269,34 \mathrm{~mm}$ em 48 horas, mas desde o dia 28 de dezembro foram 359,19 mm em 5 dias. A estação de Paraty localizada mais ao norte registrou menos chuva nos dias 31 de dezembro $(65,19 \mathrm{~mm})$ e $1^{0}$ de janeiro $(128,82 \mathrm{~mm})$, totalizando 194,01 mm em 48 horas, mas desde o dia 28 de dezembro foram 285,24 mm em 5 dias. A estação do INMET em Paraty não registrou chuvas.

Em Bananal e Cunha, municípios serranos localizados a oeste na área de estudo, as chuvas foram menos intensas nos dias 31 de dezembro (56,19 e 38,46 mm, respectivamente) e $1^{0}$ de janeiro (71,94 e 84,42 mm, respectivamente), totalizando 128,13 e $122,88 \mathrm{~mm}$, respectivamente em 48 horas, mas desde o dia 28 de dezembro foram 235,23 $\mathrm{mm}$ e 222,69 mm, respectivamente, em 5 dias. Apesar de menos intensas em Cunha, as chuvas foram responsáveis por quase 600 quedas de barreiras, inundações do rio Jacuí, que ficou cinco metros acima do normal, mataram seis pessoas e deixaram $80 \%$ dos bairros isolados afetando mais de duas mil pessoas, fazendo com que o município decretasse estado de calamidade pública (ESTADÃO, 2010).

No município de Rio Claro, ao norte de Angra dos Reis, as chuvas foram ainda menos intensas nas estações 997 e 998 nos dias 31 de dezembro de 2009 (42,18 e 55,08 mm, respectivamente) e dia $1^{\circ}$ de janeiro (18,69 e 8,28 mm, respectivamente). Os maiores registros desse período ocorreram no dia 
28 de dezembro $(82,38$ e $66,78 \mathrm{~mm}$, respectivamente). No total foram 181,95 $\mathrm{mm}$ e $155,37 \mathrm{~mm}$, respectivamente, em 5 dias.

Em Mangaratiba, estação Marambaia, mais a leste na área de estudo, os registros foram bem menores em comparação com as demais estações. A chuva mais intensa ocorreu nos dias 30 e 31 de janeiro (40,6 e 62,2 mm, respectivamente) totalizando 102,8 mm em 48 horas. Desde o dia 28 de dezembro foram 122,4 mm em 4 dias, pois no dia $1^{0}$ de janeiro não houve registro de chuva.

Na análise da carta sinótica do dia 28 de dezembro de 2009 observa-se uma ampla área de baixa pressão sobre o oeste e centro-sul do Brasil. Um cavado estende-se sobre o oceano atlântico a sudeste de São Paulo, contribuindo na organização de um canal de umidade entre o oceano e o sul do Sudeste brasileiro (Figura 5)

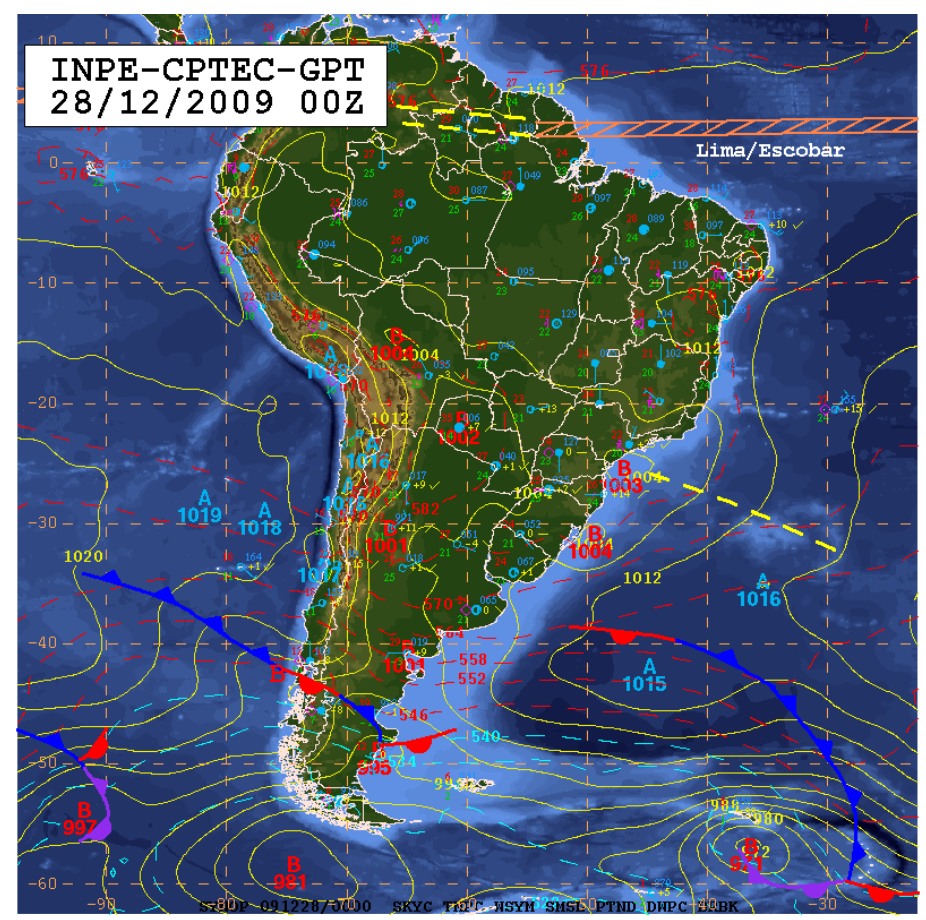

Figura 5: Carta Sinótica do dia 28/12/2009. Fonte: CPTEC/INPE.

Na análise da carta sinótica do dia 31 de dezembro de 2009 (Figura 6) observa-se dois sistemas frontais a sul de $30 \mathrm{~S}$ sobre o oceano atlântico. Uma frente oclusa também pode ser observada sobre 0 oceano atlântico em 50S, com cavados associados. Esses sistemas, juntamente com o sistema de baixa pressão atmosférica próximo à costa do estado do Rio de janeiro, mantiveram o tempo instável durante toda a semana, com céu nublado e com pancadas de chuva em grande parte do país. 


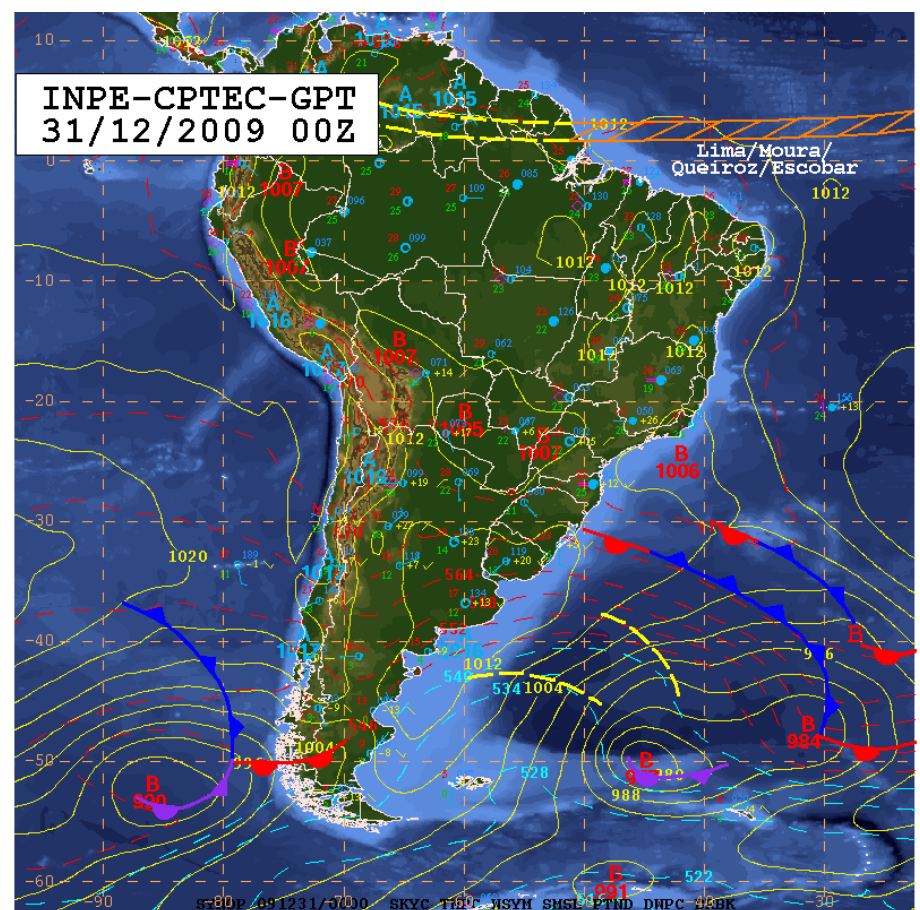

Figura 6. Carta Sinótica do dia 28/12/2009. Fonte: CPTEC/INPE

Na figura 7 é possível perceber que a precipitação acumulada nos dias 31 de dezembro de 2009 e $1^{0}$ de janeiro de 2010, se comparada com o evento de 2013 (Figura 4), foi um pouco menos intensa sobre 0 município de Angra dos Reis, mas mais intensa sobre alguns dos demais municípios, de forma generalizada como descrito anteriormente, causando estragos como queda de barreiras, soterramento de casas com perdas materiais e de vidas, em Angra dos Reis e Cunha, já mencionados anteriormente.

Espacialização da Precipitação Acumulada nos dias 31 de dezembro de 2009 e 01 de janeiro de 2010

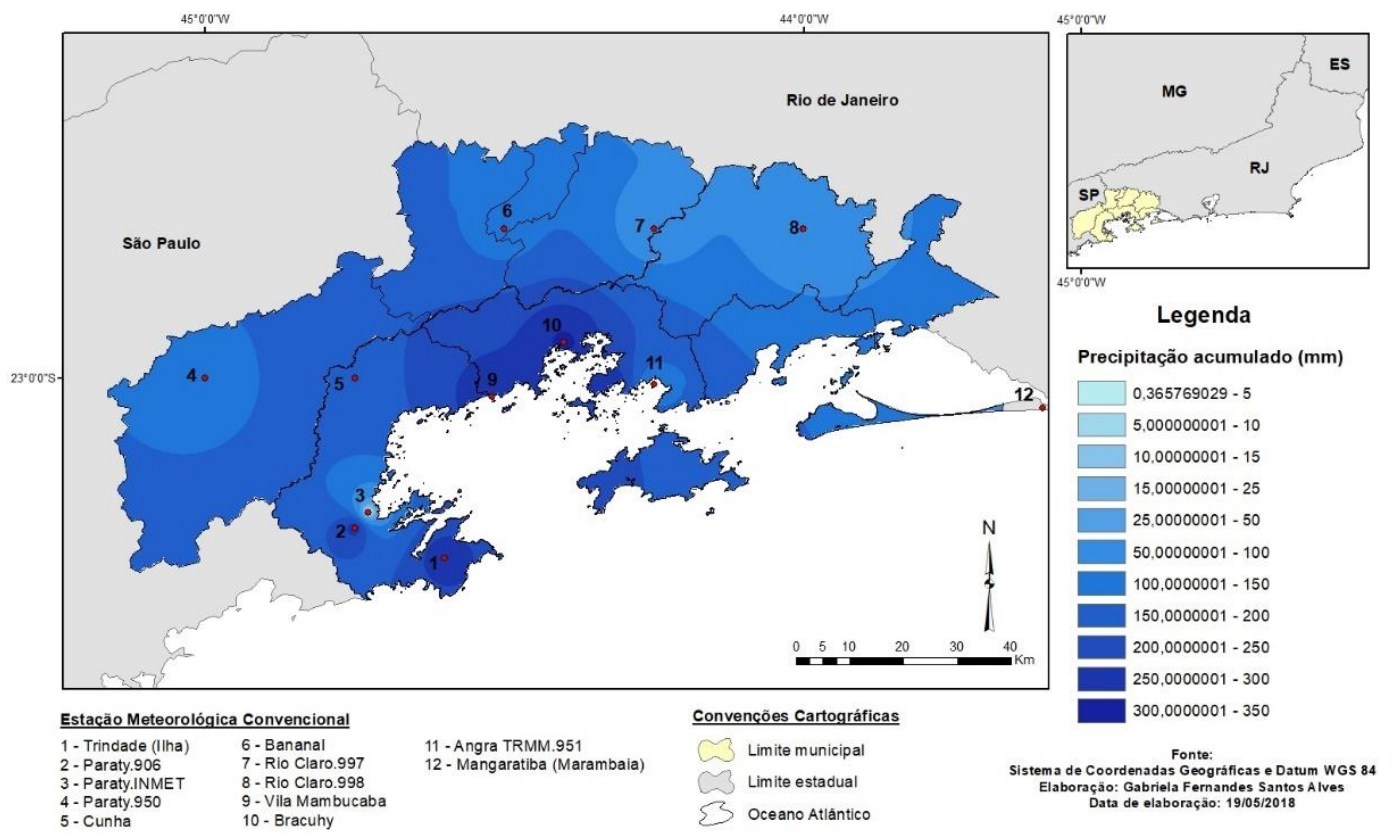


Figura 7. Espacialização da Precipitação Acumulada nos dias 31 de dezembro de 2009 e $1^{\circ}$ de janeiro de 2010.Fonte: Elaborado por Gabriela Fernandes Santos Alves

\section{Evento de 2002}

Em 2002, a chuva que desencadeou o deslizamento no dia 9 de dezembro foi bastante intensa sobre Bracuhy, tendo sido registrado um total de 181,3 $\mathrm{mm}$ em 24 horas (9 de dezembro; Tabela 7).

\begin{tabular}{|c|c|c|c|c|c|c|c|c|c|c|c|c|c|}
\hline & Dia & Trindade $^{1}$ & $\begin{array}{c}\text { Paraty } \\
906^{1}\end{array}$ & $\begin{array}{c}\text { Paraty } \\
\text { INMET }\end{array}$ & $\begin{array}{c}\text { Paraty } \\
95501^{1}\end{array}$ & Cunha $^{1}$ & Bananal $^{1}$ & $\begin{array}{c}\text { Rio } \\
\text { Claro } \\
997^{1} \\
\end{array}$ & $\begin{array}{c}\text { Rio } \\
\text { Claro } \\
\text { 9981 }^{1} \\
\end{array}$ & Mambucaba $^{1}$ & Bracuhy ${ }^{1}$ & $\begin{array}{c}\text { Angra } \\
\text { TRMM } \\
951^{3} \\
\end{array}$ & $\begin{array}{l}\text { Mangaratiba } \\
\text { Marambaia }^{1}\end{array}$ \\
\hline \multirow{8}{*}{2002} & $07 / \mathrm{dez}$ & 0 & 0 & 0 & 0 & 0 & 0 & 2.94 & 0 & 0 & 0 & 0 & 0 \\
\hline & 08/dez & 0 & 0 & 0 & 14.79 & 5.13 & 38.7 & 35.7 & 14.07 & 2.1 & 0 & 0 & 0 \\
\hline & 09/dez & 14.07 & 14.07 & 14.07 & 24.06 & 56.19 & 22.65 & 23.94 & 12.03 & 73.7 & 181.3 & 2.49 & 1.17 \\
\hline & 10/dez & 0 & 0 & 0 & 0 & 0 & 0 & 0 & 1.26 & 58.5 & 29.7 & 0 & 1.17 \\
\hline & 11/dez & 0 & 0 & 0 & 0 & 0 & 0 & 0 & 0 & 13.7 & 10.3 & 1.41 & 0 \\
\hline & $12 / \mathrm{dez}$ & 1.41 & 1.41 & 1.41 & 4.23 & 3.78 & 10.62 & 11.43 & 20.49 & 6.7 & 10.6 & 10.29 & 28.08 \\
\hline & $13 / \mathrm{dez}$ & 12.51 & 12.51 & 12.51 & 4.32 & 11.73 & 9.78 & 10.02 & 7.2 & 20.9 & 17.7 & 10.47 & 12.3 \\
\hline & $14 / \mathrm{dez}$ & 1.83 & 1.83 & 1.83 & 2.94 & 4.44 & 1.8 & 0 & 0 & 0 & 0 & 0 & 7.14 \\
\hline
\end{tabular}

Tabela 6. Registro de Chuva nas Estações Meteorológicas - Evento de 2009/10. Fonte: ${ }^{1}$ NOAA, ${ }^{2}$ INMET, ${ }^{3}$ EMBRAPA Organizado por Gabriela Fernandes Santos e Heitor Soares de Farias

Pode-se dizer que foi um evento mais concentrado, pois os registros nas demais estações são bastante inferiores, sendo os mais elevados em Mambucaba $(73,7 \mathrm{~mm})$ e Cunha $(56,19 \mathrm{~mm})$, muito menos do que o registrado no evento de 2010.

A partir da análise das cartas sinóticas do dia 9 de dezembro de 2002 (Figura 8) percebe-se a permanência de uma frente fria caracterizada pela banda de nebulosidade de orientação NW/SE, estendendo-se desde a região Amazônica até o oceano atlântico, caracterizando a atuação da Zona de Convergência do Atlântico Sul (ZCAS). 

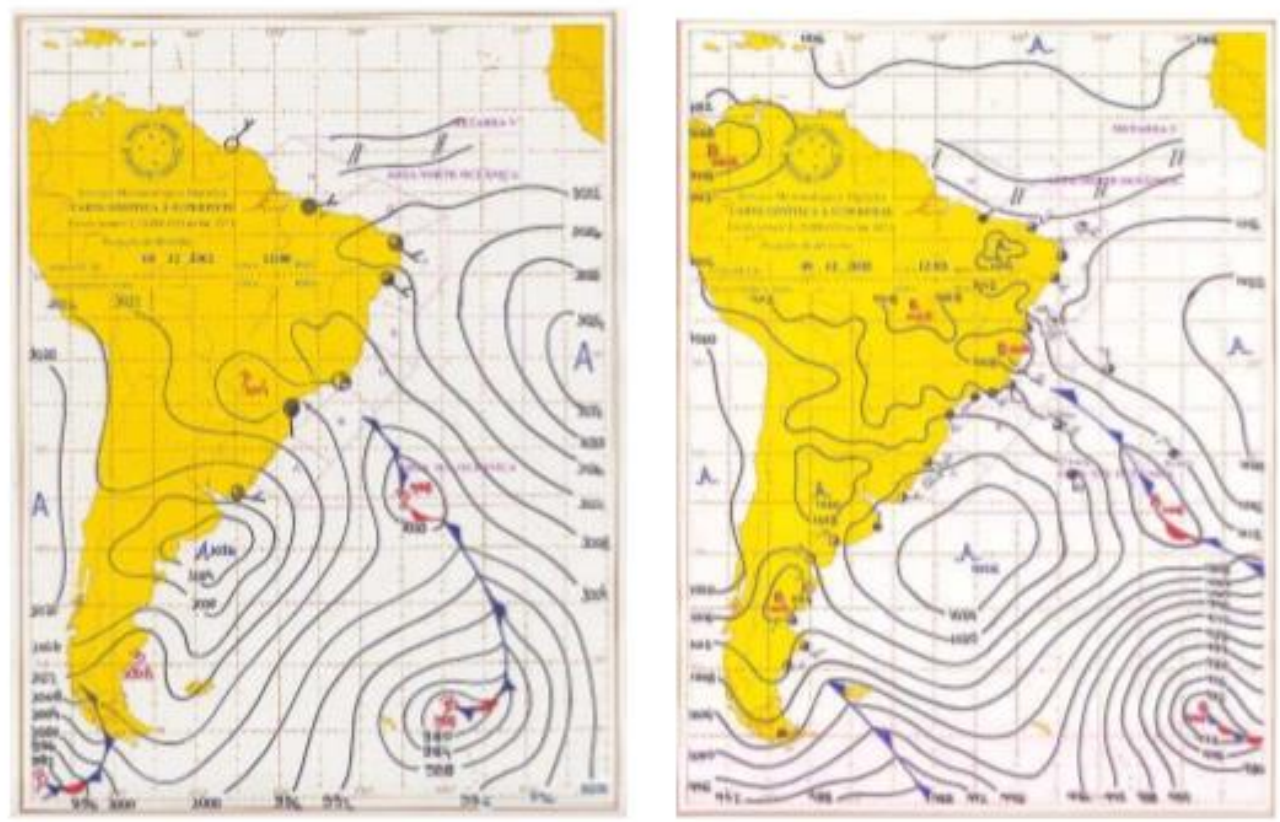

Figura 8. Carta Sinótica do dia 9/12/2009. Fonte: Marinha do Brasil

Na figura 9, a precipitação acumulada nos dias 9 e 10 de dezembro de 2002 foi bastante concentrada sobre Bracuhy, com maior intensidade sobre Angra dos Reis, mas muito menos intensa do que nos eventos que ocorreram nos anos de 2009/2010 e 2013, o que sugere a concentração de um núcleo convectivo intenso sobre a área afetada. No mapa observa-se que nas áreas mais claras a chuva foi bem fraca, como nos municípios de Rio Claro e Mangaratiba, como também destaca a tabela 7

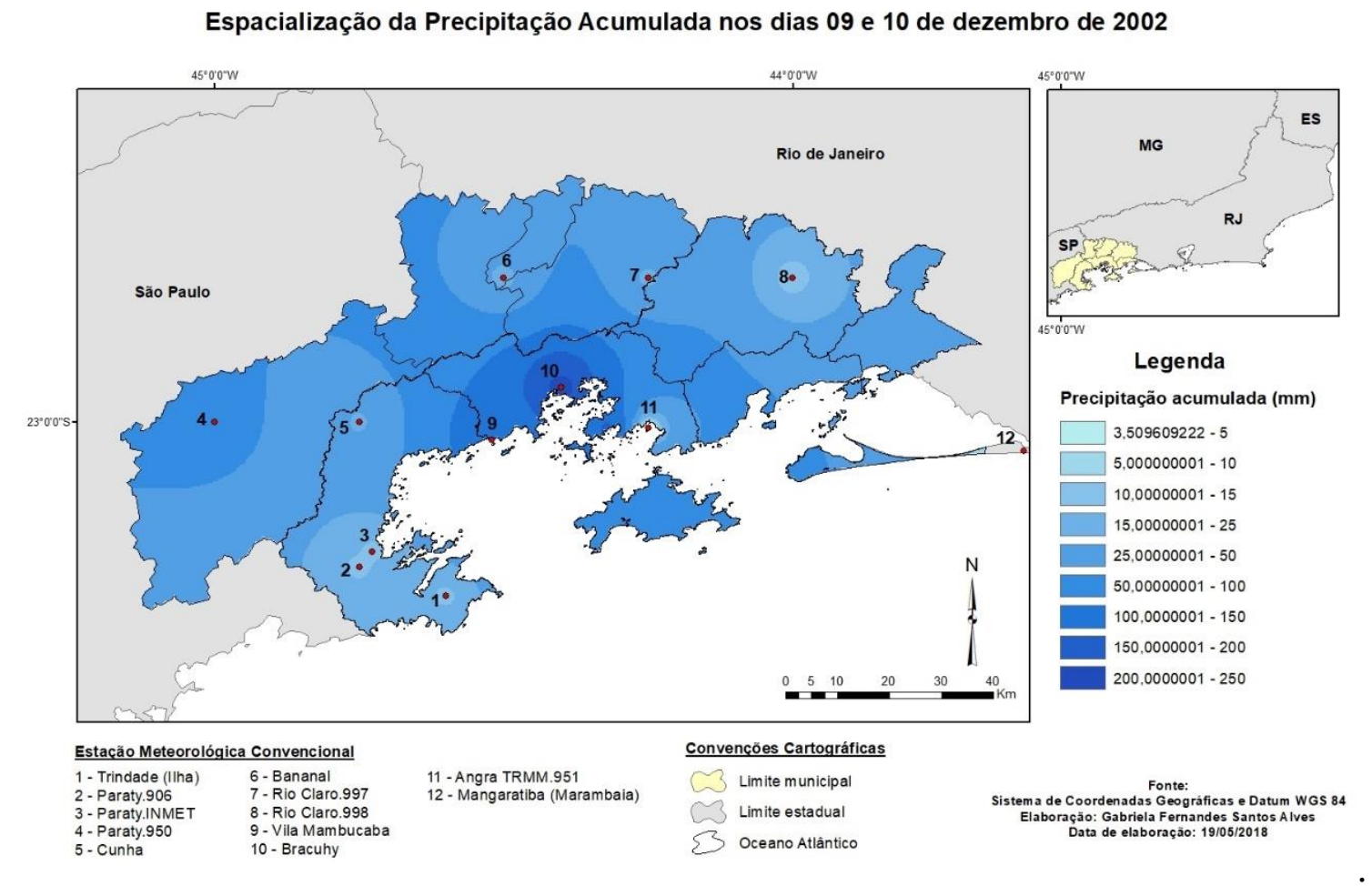


Figura 9. Espacialização da Precipitação Acumulada nos dias 9 e 10 de dezembro de 2002. Fonte: Elaborado por Gabriela Fernandes Santos Alves

\section{CONSIDERAÇÕES FINAIS}

Com o objetivo de fazer uma análise da distribuição espacial e temporal da pluviosidade na região da Costa Verde fluminense, e municípios vizinhos no estado de São Paulo, no período de 2001 a 2016, os resultados indicaram que a distribuição espacial da precipitação é significativamente influenciada pela topografia e pela distância do litoral. Nesse contexto, Angra dos Reis se encontra em uma posição confrontante ao deslocamento das frentes frias fazendo com que os máximos de precipitação ocorram a barlavento da Serra do Mar. O relevo força a elevação do ar úmido, que resfria e condensa, favorecendo a formação de nuvens e produzindo precipitação intensa, como verificado em Mambucaba e Bracuhy, onde o total anual de chuvas ultrapassou $3000 \mathrm{~mm}$ no ano de 2010.

Após a ocorrência de precipitação a barlavento da escapa, o ar torna-se mais seco e desce a barreira orográfica sendo comprimido e aquecido, inibindo a formação de nuvens e de precipitação. Portanto, as áreas a sotavento das barreiras topográficas locais apresentam índices mais reduzidos de precipitação, como ocorre na área continental, em Paraty e nos municípios situados sobre a Serra do Mar, como: Bananal, Cunha e Rio Claro que apresentam índices pluviométricos anuais inferiores a $2000 \mathrm{~mm}$.

Analisando os três eventos de catastróficos relacionados a episódios de pluviosidade intensa nos anos de 2002, 2010 e 2013, observa-se que os totais de pluviosidade registrados:

- foram maiores nos meses de dezembro e janeiro - durante o verão, período chuvoso na região Sudeste do Brasil.;

- estiveram associados a passagem de sistemas frontais, sendo um deles associado a um sistema de baixa pressão atmosférica;

- foram maiores no município de Angra dos Reis, nas estações Mambucaba e Bracuhy; 
- foram maiores a cada evento: 2002 foi intenso (Mambucaba: 132,2; Bracuhy: 211), mas 2010 foi mais (Mambucaba: 282,1; Bracuhy: 307,2) e 2013 ainda mais, sendo o mais intenso dos três (Mambucaba: 446,7; Bracuhy: 335,3).

Assim, percebe-se que os problemas enfrentados em Angra dos Reis são uma conjunção de processos naturais e sociais ocasionados pela proximidade da vertente da Serra do Mar com o oceano atlântico. Esta conformação em Angra dos Reis faz com que episódios eventuais se tornem catastróficos para uma parcela da população, normalmente aquelas que por não possuírem condições financeiras para habitarem locais mais seguros da estreita planície, acabam por ocupar as encostas, as mais afetadas por fenômenos naturais mais intensos.

É preciso que a Prefeitura de Angra dos Reis, juntamente com os governos estadual e federal, crie estratégias que impeçam a ocupação de encostas e áreas próximas aos principais rios da região, áreas suscetíveis aos efeitos das chuvas intensas, tornando-as menos vulneráveis. Além de aprimorar os já existentes sistemas de alerta à população decorrentes dos avisos meteorológicos e monitoramento das condições de tempo, promovidos pelo Centro Nacional de Monitoramento e Alertas de Desastres Naturais - CEMADEN.

\section{REFERÊNCIAS}

AKKALA, Arjun; DEVABHAKTUNI, Vijay \& KUMAR, Ashok. Interpolation techniques and associated software for environmental data. Environ. Progress Sust. Energy, 29:134-141, 2010.

DERECZYNSKI, Claudine Pereira; LUIZ SILVA, Wanderson \& MARENGO, José Antônio. Detection and Projections of Climate Change in Rio de Janeiro, Brazil. American Journal of Climate Change, v. 2, n. 1, p. 25-33. Mar. 2013.

ESTADÃO. Cunha-SP decreta estado de calamidade pública. On line. Disponível em: https://noticias.uol.com.br/ultnot/agencia/2010/01/05/ult4469u51213.jhtm. Acesso em 21 junho 2018.

FARIAS, H.S. Espaços de Risco à Saúde Humana na Região Metropolitana do Rio de Janeiro: um estudo das trajetórias de poluentes atmosféricos do Arco Metropolitano, CSA e COMPERJ. 2012. 149f. Tese (Doutorado em Geografia) Universidade Federal Fluminense, Niterói, 2012.

FARIAS, Heitor; LOUSADA, Gabriel. Desastres ambientais, prevenção e mitigação: um estudo de caso da região de Angra dos Reis/RJ. Revista Continentes (UFRRJ), v. 3, n.5, p. 131-149. Jul. 2014. 
GARDIMAN JÚNIOR, Benvindo Sirtoli; MAGALHÃES, Ivo Augusto Lopes; FREITAS, Carlos Antônio Araújo; CECÍLIO, Roberto Avelino. Análise de técnicas de interpolação para espacialização de precipitação pluvial na bacia do rio Itapemirim (ES). Ambiência, Guarapuava, v.8, n.1, p.61-71, 2012.

IBGE - Instituto Brasileiro de Geografia e Estatística. Censo Dempgráfico On line. 2010. Disponível em: https://cidades.ibge.gov.br/. Acesso em 25 junho 2018.

JIMENEZ, K. Q.; DOMECQ, F. M. Estimação de chuva usando métodos de interpolação. Porto Alegre: Instituto de Pesquisas Hidráulicas. Universidade Federal do Rio Grande do Sul, p.16, 2008 [S.I].

LANDIM, P. M. B., STURARO, J. R.; \& RIEDEL, P. S. (2000) - O emprego da técnica geoestatística da krigagem indicativa em Geotecnia Ambiental. Revista Solos e Rochas, 23(3):157-164.

LUIZ SILVA, Wanderson; DERECZYNSKI, Claudine Pereira; CHOU, Sin Chan; CAVALCANTI, Iracema. Future changes in temperature and precipitation extremes in the state of Rio de Janeiro (Brazil). American Journal of Climate Change, v. 2, n. 3, p. 353-365. Dez. 2014.

LUIZ SILVA, Wanderson e DERECZYNSKI, Claudine Pereira. Caracterização Climatológica e Tendências Observadas em Extremos Climáticos no Estado do Rio de Janeiro. Anuário do Instituto de Geociências - UFRJ, Rio de Janeiro, v. 37, n. 2, p. 123-138, 2014

LUIZ SILVA, Wanderson; NASCIMENTO, Mariana Ximenes e MENEZES, Wallace. Atmospheric Blocking in the South Atlantic during the Summer 2014: A Synoptic Analysis of the Phenomenon. Atmospheric and Climate Sciences, 5, 386393. 2015 .

MANGARATIBA, Prefeitura Municipal. Dados do Município de Mangaratiba. Disponível em: http://www.mangaratiba.rj.gov.br/novoportal/pagina/dados-do-municipio.html. Acesso em 25 junho 2018.

MINISTÉRIO DO TURISMO. Costa Verde (RJ) é eleita uma das 10 melhores regiões do mundo para viajar. On line. 2015. Disponível em: http://www.turismo.gov.br/últimas-notícias/5641-costa-verde-rj-é-eleita-uma-das-10-melhoresregiões-para-viajar.html. Acesso em 25 junho 2018.

NIMER, Edmond. Climatologia do Brasil. Rio de Janeiro: IBGE, 1979. 422 p. (Recursos naturais e meio ambiente).

O GLOBO. Na virada do ano, temporal causa 53 mortes em Angra dos Reis. On line. 2010. Disponível em: http://acervo.oglobo.globo.com/rio-de-historias/na-virada-do-ano-temporal-causa-53-mortes-em-angra-dos-reis-9244851. Acesso em 21 junho 2018.

PBMC - Painel Brasileiro de Mudanças Climáticas. Contribuição do Grupo de Trabalho 2 ao Primeiro Relatório de Avaliação Nacional do Painel Brasileiro de Mudanças Climáticas. Sumário Executivo do GT2. PBMC, Rio de Janeiro, Brasil, 2013. 28 p.

RIO CLARO, Plano Municipal De Saneamento Básico da Prefeitura de Rio Claro. On line. 2014. Disponível em: http://ceivap.org.br/saneamento/pmsb-fluminenses/pmsb-rio-claro.pdf. Acesso em 25 junho 2018.

SÃO PAULO, Governo do Estado de São Paulo. Estâncias. On line. Disponível em: http://www.saopaulo.sp.gov.br/conhecasp/praias-e-estancias/estancias/. Acesso em 21 junho 2018.

SEPPI, Inês da Cunha. Chuva provoca deslizamentos e deixa desabrigados em Angra. On line. Portal de Notícias Terra. Disponível em: https://www.terra.com.br/noticias/brasil/cidades/rj-chuva-provoca-deslizamentos-e-deixa-desabrigados-emangra,ced8ffc4daffb310VgnVCM4000009bcceb0aRCRD.html. Acesso em 21 junho 2018.

SETUR, Secretaria Estadual de Turismo do Rio de Janeiro. Mapas das Regiões Turísticas. On line. Disponível em: http://www.turisrio.rj.gov.br/projetos.asp. Acesso em 21 junho 2018. 
VIEIRA, André. Em 2002, tragédia matou 40 pessoas em Angra dos Reis. Jornal Último Segundo - IG. On line. Disponível em: http://ultimosegundo.ig.com.br/brasil/em-2002-tragedia-matou-40-pessoas-em-angra-dos-reis/n1237609910514.html. Acesso em 21 junho 2018. 